\title{
A Patient with Splenic Marginal Zone Lymphoma Presenting with Spastic Paraplegia as the Initial Symptom
}

\author{
Yuko Wada $^{\mathrm{a}}$ Yo Nishimura ${ }^{\mathrm{a}}$ Kimio Hashimoto ${ }^{\mathrm{b}}$ \\ Departments of a Neurology, and ${ }^{b}$ Pathology, Nishi-Kobe Medical Center, Kobe, \\ Japan
}

\section{Key Words}

Splenic marginal zone lymphoma · Spastic paraplegia · Spinal cord · Magnetic resonance imaging

\begin{abstract}
In this report, we describe the case of a patient with splenic marginal zone lymphoma (SMZL) who presented with spastic paraplegia as the initial symptom. A 42-year-old male developed progressive spastic paraplegia over 4 months. His neurologic examination revealed paraplegia with pyramidal syndrome, hypoesthesia below the T1 level, and anal hypotonia. Magnetic resonance imaging (MRI) of the spinal cord revealed an extensive high-intensity signal in T2-weighted sequences and swelling involving the thoracic region and conus medullaris. A laboratory test revealed presence of the serum $M$ component. Abdominal computed tomography images showed moderate splenomegaly. Abnormal lymphocytes of B-cell lineage markers (CD19+, CD20+, and CD25+; surface immunoglobulin $\mathrm{k}$ expression; $\lg \mathrm{D}+$ and $\lg \mathrm{M}+$ ) were found in the peripheral blood, cerebrospinal fluid, bone marrow and spleen. Splenectomy confirmed the SMZL diagnosis. After the completion of chemotherapy, the patient was in complete remission, and spinal MRI findings were normal. Intramedullary spinal cord involvement in SMZL is extremely rare, and, to the best of our knowledge, this is the first case of SMZL with intramedullary spinal cord involvement associated with clinical and radiologic signs without the involvement of cerebral structures. Spastic paraplegia can be the initial presentation of SMZL.
\end{abstract}

\section{Introduction}

Splenic marginal zone lymphoma (SMZL) is a well-defined low-grade B-cell nonHodgkin's lymphoma that primarily affects the white and red pulps of the spleen [1]. Patients with this disease are typically elderly men, and this tumor usually involves the 
bone marrow, liver, and splenic hilar lymph nodes [1]. Involvement of the central nervous system (CNS) in the initial stage is rare in SMZL, and only a few cases of meningeal lymphomatosis as the first manifestation of SMZL have been reported in the literature [2, 3]. We report on the unique case of a patient with SMZL presenting with spastic paraplegia as the initial symptom.

\section{Case Report}

A 42-year-old male patient with no history of illness was admitted to our hospital because of progressive spastic paraplegia over 4 months. In November 2004, he noticed paresthesia in the soles of his feet. In February 2005, he developed paresthesia in both hands, spasticity of his legs, and paresthesia below the T10 level. Over the next few months, he noted a progressive worsening of spastic paraplegia and sensory disturbance at the T1 sensory level. On admission, neurologic examinations revealed paraplegia with pyramidal syndrome, hypoesthesia below the T1 level, and anal hypotonia. Other examinations showed normal results. WBC count was 5,700/dl, with $46 \%$ lymphocytes ( $19 \%$ of which were atypical). Viral and bacterial test results and the LDH level were normal. Serum protein electrophoresis revealed the presence of an IgM paraprotein. The level of a soluble anti-interleukin-2 receptor antibody was elevated $(3,830 \mathrm{U} / \mathrm{ml})$. The nerve conduction study yielded normal results. Spinal cord magnetic resonance imaging (MRI) revealed an extensive high-intensity signal in T2-weighted sequences and swelling involving the thoracic region (from T1 to T12) and conus medullaris (fig. 1). There was no gadolinium enhancement in T1-weighted sequences. Brain MRI findings were normal. Cerebrospinal fluid (CSF) examination showed a high protein level with atypical lymphocytes. Flow cytometry of peripheral blood and CSF showed B-lineage markers (CD19+, CD20+, and CD25+; surface immunoglobulin $\kappa$ expression; IgD+ and IgM+, CD5- and CD103-). Abdominal computed tomography (CT) images showed moderate splenomegaly (fig. 2). No peripheral lymphadenopathy or hepatomegaly was detected. Splenectomy was performed. A histopathological analysis of the spleen showed typical white pulp lymphocyte infiltration (fig. 2). The lymphoid cells exhibited the same phenotypic B-lymphocyte infiltration as in the peripheral blood, CSF, and bone marrow. The diagnosis of SMZL was established. Intrathecal cytarabine, methotrexate, hydrocortisone sodium phosphate, systemic fludarabine phosphate, and rituximab were administered.

Three months after the completion of chemotherapy, the patient was in complete remission, and follow-up spinal MRI findings were normal (fig. 1). Five years after the diagnosis, the patient remains in complete remission and his neurologic examination findings are almost normal.

\section{Discussion}

We report on the unique case of a patient with SMZL with spinal involvement presenting with spastic paraplegia as the initial symptom. In our patient, the rapid diagnosis enabled the immediate initiation of chemotherapy, which led to clinical stability and radiologic improvements.

SMZL is a rare but distinctive and well-defined low-grade B-cell non-Hodgkin's lymphoma that primarily affects the white and red pulps of the spleen [1]. The clinical symptoms of SMZL are nonspecific; e.g. fatigue, moderate anemia, abdominal symptoms due to splenomegaly and lymphocytosis as incidental findings. CNS involvement is a common complication of high-grade lymphoma, but is rare in mature B-cell malignancies such as SMZL [4]; however, it can occur in the advanced stage [4, 5]. Our patient presented with spastic paraplegia as the initial symptom. The CNS involvements in SMZL, as previously reported, were leptomeningeal involvement [2-4] and intracerebral tumor [5]. Of the four previously reported cases of patients with SMZL,only two patients showed neurological symptoms as the initial manifestations $[2,3]$. These two patients presented with leptomeningeal involvement, and the clinical manifestations of these two 
cases were polyradiculoneuropathy [2] and papilledema [3]. Our patient showed intramedullary spinal cord involvement as determined by MRI. In the four reported cases of SMZL with CNS involvement, three [3-5] showed abnormal MRI findings. The patient of Bruna et al. [3] showed tumoral infiltration in both the optic nerves and cervicodorsal meninges. That of Gotlib et al. [4] showed multiple meningeal nodules around the posterior fossa. That of Thoennissen et al. [5] showed multiple intracerebral tumor lesions. Intramedullary spinal cord involvement in SMZL is extremely rare, and, to the best of our knowledge, this is the first case of SMZL with intramedullary spinal cord involvement associated with clinical and radiologic signs without the involvement of cerebral structures.

It is uncertain why clinical CNS involvement is rare in B-cell lymphoproliferative disorders. Yamazaki et al. [2] suggested that the low expression level of adhesion receptors of B-lymphocytes might explain the low frequency of meningeal involvement.

Our patient is still alive after 5 years and imaging studies confirmed him to be in complete remission. SMZL is generally considered to be of low grade, with some reported patients having a long-term survival, while others have an aggressive course with death within 1 year of diagnosis [1]. In the reported SMZL cases with meningeal involvement $[3,4]$, the outcomes were not good. Bruna et al. [4] suggested that CNS involvement indicates a poor prognosis. Further studies on the clinical and morphologic characteristics of SMZL are required to prevent recurrence and disease-related death. CNS involvement associated with SMZL is rare, and symptomatic involvement is even more so. Thus, physicians should take into account the possibility of CNS invasion in SMZL or other mature B-cell proliferative malignancies when patients present with neurologic manifestations. 


\begin{tabular}{c|l|l|l}
$\begin{array}{c}\text { Case Reports in } \\
\text { NeUlology }\end{array}$ & $\begin{array}{l}\text { Case Rep Neurol 2011;3:39-44 } \\
\text { DOI: 10.1159/000324446 }\end{array}$ & $\begin{array}{l}\text { Published online: } \\
\text { January 29, 2011 }\end{array}$ & $\begin{array}{l}\text { O 2011 S. Karger AG, Basel } \\
\text { ISSN 1662-680X } \\
\text { www.karger.com/crn }\end{array}$ \\
\hline
\end{tabular}
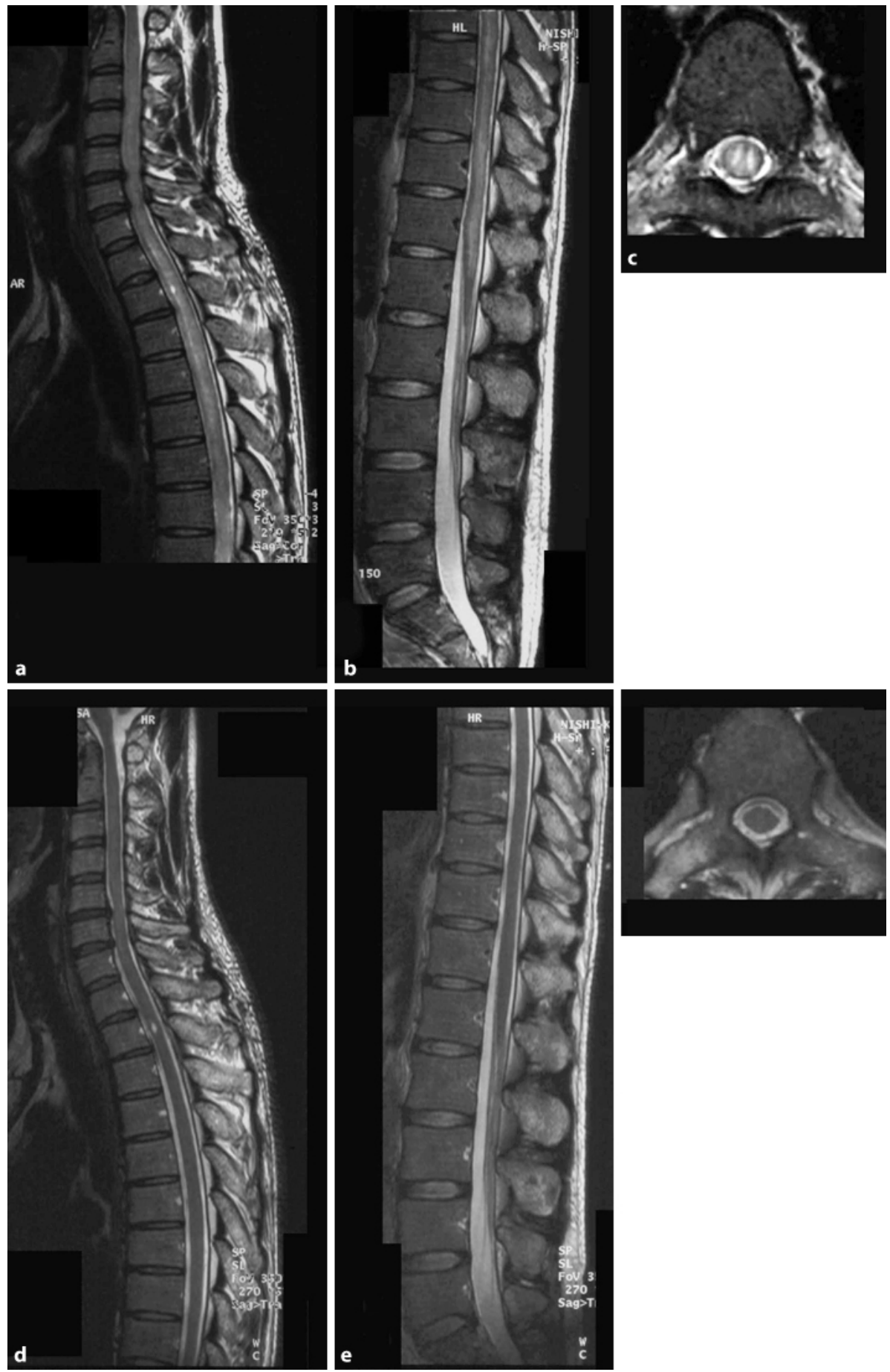

Fig. 1. a, b Sagittal T2-weighted MR images showing enlargement of the thoracic cord at the T1-T12 levels and conus medullaris associated with high signal intensity. c Axial T2-weighted MR image showing central signal intensity abnormality in cord at the T4 level. d, e Sagittal T2-weighted MR images after treatment. Abnormal lesions have completely disappeared. f Axial T2-weighted MR image after treatment. Abnormal lesions have completely disappeared. 


\begin{tabular}{c|l|l|l}
$\begin{array}{c}\text { Case Reports in } \\
\text { Neurology }\end{array}$ & $\begin{array}{l}\text { Case Rep Neurol 2011;3:39-44 } \\
\text { DOI: 10.1159/000324446 }\end{array}$ & $\begin{array}{l}\text { Published online: } \\
\text { January 29, 2011 }\end{array}$ & $\begin{array}{l}\text { O 2011 S. Karger AG, Basel } \\
\text { ISSN 1662-680X } \\
\text { www.karger.com/crn }\end{array}$ \\
\hline
\end{tabular}
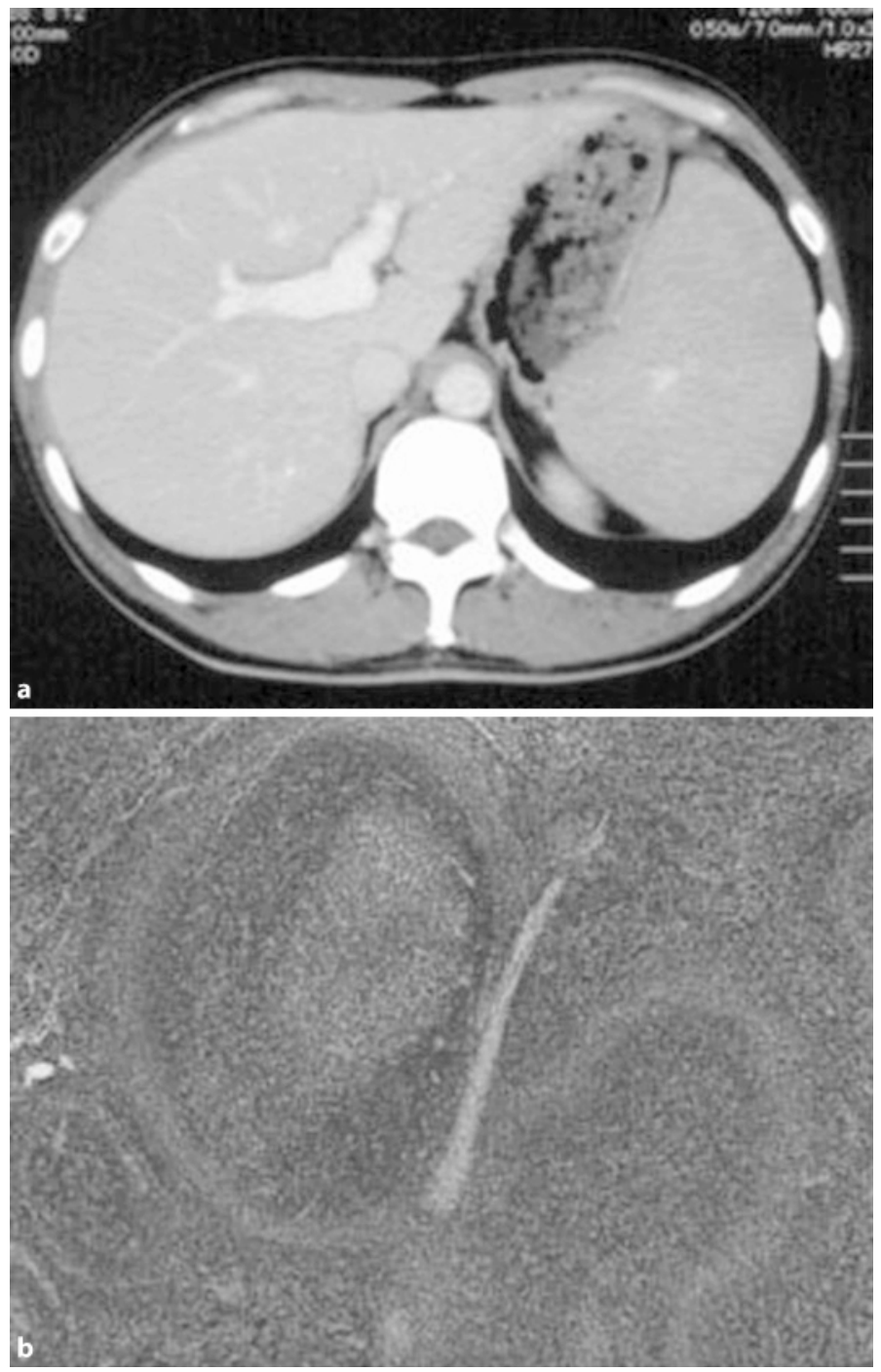

Fig. 2. a Abdominal CT scan showing moderate splenomegaly. b Spleen section showing prominent white pulp infiltration by lymphocytes with marginal zone expansion (HE staining; original magnification $\times 40)$. 


\section{References}

1 Depowski PL, Dunn H, Purdy S, Ross JS, Nazeer T: Splenic marginal zone lymphoma. A case report and review of the literature. Arch Pathol Lab Med 2002;126:214-216.

-2 Yamazaki K, Shimizu S, Negami T, Sawada K, Nanasawa H, Ohta M, Konda S, Okuda K: Leukemic meningitis in a patient with splenic lymphoma with villous lymphocytes (SLVL). Cancer 1994;73:61-65.

-3 Bruna J, Martinez-Yelamos S, Alonso E, Romagosa R, Arruga J, Fernandaz S, Domingo A, Rojas-Marcos I, Petit J, Rubio F: Meningeal lymphomatosis as the first manifestation of splenic marginal zone lymphoma. Int J Hematol 2005;82:63-65.

-4 Gotlib V, Singareddy S, Gergis U, Vakios J, Guevara E, Chadburn A, Yavarkovsky LL, Patel A, Butt A, Nayak A: Leptomeningeal involvement in a patient with splenic lymphoma with villous lymphocytes. Leuk Lymphoma 2002;43:1337-1340.

5 Thoennissen NH, Keyvani K, Voelker HU, Bremer J, Krug U, Muller-Tidow C, Koch P, Muller-Hermelink HK, Berdel WE: Splenic marginal zone lymphoma: transformation to diffuse large B-cell lymphoma with isolated cerebral manifestation. J Clin Oncol 2008;20:4509-4511. 